\title{
A família no cuidado em saúde mental: desafios para a produção de vidas
}

\author{
The family in mental health care: challenges for the production of lives
}

\author{
Thayane Pereira da Silva Ferreira', Juliana Sampaio², Isaac Linhares de Oliveira $\mathbf{3}$, Luciano Bezerra \\ Gomes $^{2}$
}

DOI: 10.1590/0103-1104201912112

RESUMO O estudo problematiza o lugar das famílias na produção do cuidado em saúde mental. De caráter qualitativo, foi desenvolvido a partir da produção de narrativas e vivências em um Centro de Atenção Psicossocial (Caps), tipo III, de João Pessoa-PB, entre fevereiro e novembro de 2015. Os pesquisadores acompanharam a produção de cuidado para um usuário denominado 'o Capoeirista'. A partir de então, produziram-se novas visibilidades para a família na produção do cuidado: 1. Família como espaço de disputa de plano de cuidado; 2. Família que também precisa ser cuidada; e 3. Família como parte da vida social do usuário. Nesse sentido, o Caps precisa redefinir o perfil do seu usuário, extrapolando do âmbito individual para o familiar.

PALAVRAS-CHAVE Saúde mental. Serviços de saúde mental. Assistência à saúde mental.

\begin{abstract}
The study rise questions about the place of families in the production of mental health care. Of qualitative character, it was developed from the production of narratives and experiences in a Psychosocial Care Center (Caps), type III, of João Pessoa-PB, between February and November of 2015. The researchers followed the production of care for a user called 'the Capoeirista'. Since then, new visibilities have been produced for the family in the production of care: 1. Family as a space for a care plan dispute; 2. Family that also needs to be cared for; and 3. Family as part of the user's social life. In this sense, Caps needs to re-define the profile of its user, extrapolating from the individual to the familiar.
\end{abstract}

Universidade Federal da Paraíba (UFPB), Departamento de Terapia Ocupacional - João Pessoa (PB), Brasil. thayane.silva01@hotmail. com

2 Universidade Federal da Paraíba (UFPB)

Departamento de

Promoção da Saúde - João

Pessoa (PB), Brasil.

3 Universidade Federal da Paraíba (UFPB) - João

Pessoa (PB), Brasil.
KEYWORDS Mental health. Mental health services. Mental health assistance. 


\section{Introdução}

Este estudo convida o leitor a uma produção de sentidos sobre o lugar da família na produção do cuidado em saúde mental. Toma como orientação desses sentidos a compreensão de família como um sistema aberto e interconectado com outras estruturas sociais e outros sistemas que compõem a sociedade $\mathbf{1}$. A família é constituída por um grupo de pessoas que estabelecem relações de cuidado, de conflitos, vínculos e convivência cotidiana, que possibilitam aos indivíduos se sentirem pertencente a um grupo.

Ao olhar de perto para o conjunto dos arranjos familiares, serão visualizadas multidões ${ }^{2}$, constituídas por diferentes indivíduos que se conectam pelos afetos, crenças, hábitos e regras de convivência. Ver-se-á, também, que a multidimensionalidade de uma família traz consigo a sua unicidade, representada pelos modos singulares que os indivíduos estabelecem na sua dinâmica familiar.

Partindo dessa produção de sentidos sobre as famílias, percebe-se que, além dos aspectos já citados, outros devem ser considerados, como sua rotina, seus acordos relacionais e os papéis que cada sujeito assume em sua organização. Tais fios vão se conectando em rizoma ${ }^{3}$, de modo a constituírem uma rede, onde cada sujeito é parte da família, e a família faz parte dele.

Nessa relação entre o sujeito e sua família, a Política Nacional de Saúde Mental (PNSM), fruto da reforma psiquiátrica brasileira, redirecionou os modos de produção de cuidado em saúde mental, no sentido de conceber e entender o papel da família no cuidado dos sujeitos com transtorno mental ${ }^{1,4}$. Se, antes, o tratamento se dava por meio do isolamento do indivíduo do seio familiar e comunitário, agora, ele deve ser realizado em serviços de base territorial, como os Centros de Atenção Psicossocial (Caps), e na Atenção Básica à Saúde (ABS), por meio da equipe de saúde da família, entre outros'.

Essa mudança garante ao sujeito com transtorno mental viver junto à sua família, circular pelo território e estabelecer relações com as redes sociais e de apoio que a comunidade oferece ${ }^{5}$. Dentro dessa nova perspectiva, a família pode ser requisitada como parceira dos novos serviços e reafirmada como um dos possíveis espaços do provimento de cuidado ${ }^{6}$, podendo ser necessária e aliada no cuidado de seu familiar em sofrimento psíquico ${ }^{1}$.

A família passa a ser convocada a integrar as redes de apoio do usuário, e, como tal, deve ser considerada na produção do cuidado, de modo que não seja apenas acionada para o atendimento do sujeito, mas também possa fazer parte das ações. A abordagem familiar tem sido uma aposta das equipes de saúde da família, reafirmando a necessidade de sua inclusão na produção do cuidado ${ }^{7}$. Nos Caps, a lógica da desinstitucionalização, enquanto desconstrução de um modelo hegemônico de cuidado centrado nos hospitais psiquiátricos reconhece também a família como espaço que cuida e precisa ser cuidado. Entretanto, a abordagem familiar ainda é um desafio nas práticas cotidianas desses serviços substitutivos.

Entendendo que o cuidado deva ser produzido em redes e que possibilite a sustentabilidade cotidiana do indivíduo no território e a produção de vida ${ }^{8}$, o presente texto tem como objetivo problematizar o lugar que as famílias assumem na dinâmica dos Caps e suas implicações para a produção do cuidado para além dos muros institucionais.

\section{Percurso cartográfico}

Os encontros e suas afecções guiaram o percurso metodológico do estudo, na medida em que foram sendo utilizadas diversas estratégias de produção de narrativas e vivências, em consonância com as demandas oriundas do campo. Inicialmente, duas pesquisadoras apoiadoras negociaram sua aproximação com um Caps III do município, participando, durante os meses de fevereiro a novembro de 2015, das reuniões semanais de equipe, 
nas quais também ocorria quinzenalmente supervisão clínico-institucional com uma supervisora externa ao serviço.

Nessas reuniões, as pesquisadoras apoiadoras puderam acompanhar discussões gerenciais e administrativas do serviço e participar, inclusive colaborando com o debate, de discussões sobre a organização do processo de trabalho da equipe, condições clínico-existenciais de usuários e seus projetos terapêuticos, além de discussões teóricas sobre temas correlatos às questões vivenciadas pelo serviço.

Foi, assim, assumida a perspectiva de pesquisadores in-mundo ${ }^{2}$, a partir da qual se reconhecem e tomam-se como produtos de análise as diversas implicações e sobreimplicações dos pesquisadores, e valoriza-se sua imersão no mundo sobre o qual deseja produzir sentidos. Tal posicionamento epistemológico permitiu que alguns profissionais do serviço, atendendo ao convite da pesquisa, passassem a acompanhá-la mais de perto, tornando-se, também, seus pesquisadores. Nesse sentido, estes assumiram que o produto da pesquisa nada mais pode ser além de um conjunto de sentidos produzidos nos encontros e suas afecções.

Ao participarem das reuniões de equipe do serviço, os pesquisadores puderam rastrear' a produção do cuidado dentro e fora do Caps. Entre os vários acontecimentos rastreados ali, os pesquisadores foram convocados a analisar os seus encontros com um usuário que frequentemente aparecia nos relatos e discursos dos trabalhadores. Era apontado como alguém 'difícil de lidar', e sua família vista como 'quem não contribuía para o tratamento'.

Os sentidos produzidos nesse relato se deram a partir da cartografia ${ }^{9}$ de encontros e conversas travados entre pesquisadores, profissionais, usuários e familiares, que foram processados (discutidos) nos encontros do coletivo de pesquisadores. A composição desse coletivo por diferentes atores reafirmou e consolidou a aposta compartilhada da pesquisa.

Atendendo às exigências éticas de pesquisas envolvendo seres humanos, foi solicitada a assinatura do Termo de Consentimento Livre e Esclarecido (TCLE) de todas as pessoas envolvidas no estudo. O projeto foi aprovado pelo Comitê de Ética em Pesquisa (CEP) da Universidade Federal da Paraíba (UFPB), sob o CAAE 42554815.0.0000.5188, atendendo aos princípios éticos da Resolução ${ }^{\circ} 466 / 12$ do Conselho Nacional de Saúde.

\section{Rastreando diferentes lugares da família na produção do cuidado em saúde mental}

No percurso da vivência junto à equipe do Caps, algumas cenas da produção do cuidado do serviço foram rastreadas e processadas, trazendo para o debate o lugar da família na produção do cuidado em saúde mental. Entendendo que o cuidado é um acontecimento e não um ato ${ }^{10}$, descrevemos abaixo um 'acontecimento' que emergiu no cotidiano do serviço, sendo vivenciado pelo conjunto de pesquisadores que participaram da pesquisa compartilhada.

\section{O acontecimento}

Capoeirista é um jovem de vinte e poucos anos e filho único. Frequenta o Caps há alguns anos, sendo diagnosticado pelo médico psiquiatra do serviço como um sujeito com esquizofrenia e retardo mental moderado. Ele quase sempre é pauta de discussão das reuniões de equipe, visto que é muito agitado, "chega no serviço a hora que quer, faz o que bem quer, e na hora que quer", como afirma um dos técnicos do Caps.

Para além do transtorno psíquico e de sua 'indisciplina' no serviço, a equipe traz elementos importantes sobre a vida familiar de Capoeirista, que parecem desembocar nas dificuldades da equipe em lidar com ele. $\mathrm{Na}$ época da gravidez de Capoeirista, sua mãe, casada há algum tempo, suspeita que está com um tumor e inicia um tratamento medicamentoso, descobrindo somente após alguns 
meses que estava grávida. A equipe relata que, atualmente, seus pais têm uma relação conflituosa e uma enorme dificuldade de aceitação de Capoeirista.

Segundo os relatos dos técnicos mais próximos a ele, um educador físico e o professor de capoeira, o Caps tem assumido um lugar de refúgio para Capoeirista, que, ao vivenciar as situações de conflito em casa, busca o serviço. Não importa a hora e a distância, visto que ele mora em um outro bairro, um pouco distante. A equipe reconhece, assim, que o serviço funciona como um 'local de escape' para Capoeirista, na medida em que existem muitos conflitos no seu ambiente familiar.

Nas diversas discussões sobre esse usuário, são produzidos relatos de que as mesmas posturas e atitudes que este tem em casa (de mandar na mãe, agredi-la verbalmente e fisicamente) estão sendo, de certo modo, reproduzidas no Caps na relação com a equipe. $\mathrm{O}$ educador físico aponta que Capoeirista chegou a relatar que sua mãe sofre agressões por parte do seu pai, e que por isso ele fica muito agitado.

Os relatos são tecidos à medida que novos elementos são incorporados na história da vida familiar de Capoeirista, constituindo uma rede com relações conflituosas e de rupturas. Por vezes, alguns profissionais responsabilizam a família, que não cuida dele, restando ao Caps assumir o seu cuidado. Nesse movimento, foi acionado o Ministério Público, para tomar o que, para os profissionais do Caps, seriam as 'devidas providências' sobre o 'descuidado' da família com Capoeirista.

O prosseguimento e os possíveis encaminhamentos do 'caso de Capoeirista' foram discutidos em reunião pela equipe do Caps, na qual cada profissional apontou uma proposta de plano de cuidado para ele e sua família. Essa construção não contou com a participação dos sujeitos para quem se dirigia o referido plano, visto que ia sendo tecida nos encontros entre os trabalhadores e nas reuniões de supervisão clínica institucional.

A proposta do Caps consistiu em: (1) a equipe de saúde tentar uma aproximação com a família, para entender os seus conflitos e suas possíveis interferências nas posturas assumidas por Capoeirista no serviço, como também em buscar responsabilizá-la pelo cuidado ao usuário; (2) viabilizar a participação do usuário em um grupo de capoeira, próximo à sua casa, tendo em vista a necessidade de se pensar o cuidado no território e no seu cotidiano; (3) tentar inseri-lo numa escola, visto que a equipe entendia que o usuário ainda era muito jovem e poderia estar ocupando esse tempo/espaço com aprendizagem; (4) viabilizar a ida de sua mãe para um centro de práticas integrativas e complementares, tendo em vista que, na visão da equipe, ela necessitava de cuidado, pelo fato de conviver com muitos conflitos familiares. A equipe pensou que a ida da mãe de Capoeirista a esse centro poderia se dar nos dias e horários em que ele se encontrava no Caps.

Após pactuação entre a equipe de saúde, as ações foram iniciadas. A implicação da equipe no cuidado se reafirmava à medida que as ações iam sendo viabilizadas. No entanto, trazer a família para participar do projeto terapêutico parecia ser um desafio, que muitas vezes escapava da responsabilização da equipe pelo cuidado.

(1) A família pouco mostrava-se incomodada com as posturas de Capoeirista, e a equipe não conseguiu aproximar-se dela para tentar responsabilizá-la pelo cuidado dele, visto que se tratava de uma demanda da equipe; (2) a viabilização da participação do usuário no grupo de capoeira contou com a resistência de alguns membros do grupo, que, ao serem informados que Capoeirista era usuário do Caps, mostraram-se inseguros e com medo de que este causasse algum problema. No entanto, sua participação foi negociada pelo professor de capoeira do Caps, que se responsabilizou por ele, mediando as suas relações com o grupo; (3) após algumas tentativas da equipe, foi possível matricular Capoeirista no programa de Educação de Jovens e Adultos. No entanto, a equipe mostrava-se preocupada com a efetivação dessa aposta de cuidado, tendo em vista que a sua ida dependia da interlocução e do apoio da família, e eles 
visualizavam a família como 'negligenciadora' desse cuidado; (4) E, por fim, não foi efetivada a aposta de a mãe participar do centro de práticas alternativas e complementares, já que essa proposta pouco reverberou nas apostas que a própria mãe fazia para viver.

Tal acontecimento mobilizou os pesquisadores, na medida em que possibilitou pôr em análise as afecções e os ruídos neles produzidos. A partir desse lugar de pesquisadores afetados, foi possível produzir novas visibilidades sobre o lugar da família na produção do cuidado: 1. Família como espaço de disputa de plano de cuidado, entre si e com a equipe; 2. Família que também precisa ser cuidada e que vivencia processos de adoecimento; e 3. Família como parte da vida social do usuário, que compõe sua rede de convivência social.

\section{A família como espaço de disputa de plano de cuidado, entre si e com a equipe de saúde}

A análise desse acontecimento traz para o debate as apostas que os usuários fazem para se produzirem cotidianamente, e que muitas vezes podem divergir dos pontos de vista dos trabalhadores de saúde sobre os mesmos ${ }^{2}$. Além disso, é possível perceber na família disputas de projetos de vida e cuidado, que se estabelecem nas relações entre Capoeirista e seus pais.

Essa disputa se dá tendo em vista o modo como as relações são estabelecidas no ambiente familiar, de modo que existem relações conflituosas entre a mãe e o pai de Capoeirista. E este, ao vivenciar os conflitos, demanda a atenção dos pais, agredindo-se e quebrando objetos, como forma de mediar tais situações.

Em alguns casos, a família que vivencia disputas de modos de como levar a vida entre seus próprios membros é vista como 'quem atrapalha o cuidado', ou 'quem não coopera para a melhora do sujeito'. Em alguns momentos, como, por exemplo, na elaboração de um plano de cuidado para o seu membro, a família pode não integrar o seu planejamento, ou porque a equipe de saúde não reconhece o seu saber e suas contribuições no cuidado ${ }^{10}$ ou porque essa família não se visualiza como participante desse processo.

Nos Caps, a família pode assumir diferentes papéis no cuidado de seu parente que vivencia sofrimento psíquico, visto que essa, algumas vezes, é responsabilizada pelo usuário e pela sua melhora, todavia, ao mesmo tempo, não é vista como aquela que pode opinar e auxiliar na elaboração do projeto terapêutico do sujeito, buscando estratégias de inserção deste na comunidade, e assim por diante.

Dialogando com a atenção domiciliar, podemos encontrar semelhanças na produção do cuidado em saúde mental a partir dos serviços substitutivos, entre eles, o Caps. Carvalho ${ }^{10}$ aponta que o deslocamento das ações de cuidado do hospital para o domicílio desloca, também, os próprios trabalhadores da saúde, que precisam repensar suas práticas, desterritorializar-se/reterritorializar- $\mathrm{se}^{3} \mathrm{dos}$ seus saberes técnicos adquiridos, para encontrarem-se com o outro, que agora encontra-se na sua residência, ocupando espaços singulares e de produção da sua subjetividade"1.

Este debate convida a pensar também a produção do cuidado em saúde mental, a partir de Capoeirista, uma vez que a equipe enxergava sua família como aquela que precisava se responsabilizar pelo usuário. No entanto, não conseguia convocá-la para a construção do plano de cuidado, apesar de entenderem a participação da família como necessária para a melhora do sujeito.

As questões apontadas não desconsideram a implicação da equipe no cuidado prestado ao Capoeirista. No entanto, revela como a gestão do cuidado, em algumas situações, é realizada sobre o usuário e não com ele.

Nesse sentido, a autonomia do usuário e de sua família deve permear as ações em saúde, no sentido de que os profissionais considerem e reconheçam as apostas que os sujeitos fazem no seu cotidiano, para garantir a produção de mais vida na sua existênciaa, ${ }^{2,310}$. 


\section{A família que vivencia processos de adoecimento e precisa de cuidado}

No processamento desse acontecimento, discute-se sobre como, muitas vezes, na visão dos profissionais de saúde, os usuários assumem o lugar cristalizado de sintoma da família, de modo que o ambiente familiar pode se tornar um espaço de agudização do seu sofrimento psíquico. Nesse contexto, torna-se um desafio para a equipe de saúde lidar com as questões de sofrimento do usuário, quando seu ambiente familiar se encontra também adoecido.

Na produção de novos sentidos para essa experiência de Capoeirista e sua família, alguns pesquisadores problematizaram com a equipe a necessidade de se pensar o cuidado familiar, e não apenas individual. Entre debates e tensões, algumas falas sustentam a falta de implicação da família no cuidado de Capoeirista, mas outras afirmam que a família também precisa ser cuidada pelo Caps.

$O$ reconhecimento de que o ambiente familiar é adoecedor perpassa as discussões sobre Capoeirista e sua família. No entanto, apenas esse reconhecimento não garante que esta seja cuidada, tendo em vista que os trabalhadores não conseguem, por diversos motivos que podem escapar da implicação da equipe, construir um projeto terapêutico familiar, com articulações no território, por meio da estratégia de saúde da família, em busca do compartilhamento do cuidado ${ }^{\mathbf{1 2}}$.

Esse acontecimento convoca à problematização de que muitas vezes o ambiente familiar encontra-se adoecido, e que o indivíduo que chega ao serviço de saúde traz esse adoecimento consigo ${ }^{5}$, de modo que, quando o processo de trabalho do Caps encontra-se voltado para a atenção à família do usuário, no sentido de compreender quem são as pessoas que constituem o ambiente familiar e como se organizam, torna-se possível integrá-la ao cuidado.

A integralidade do cuidado ao indivíduo envolve, também, sua família, uma vez que esta traz em si as suas experiências e os modos de viver a vida, que são singulares e interferem nos modos de lidar com os processos saúde-doença de seus membros ${ }^{13}$.

Pelo fato de a família constituir as redes primárias do indivíduo ${ }^{\mathbf{1 4}}$, elas devem ser vistas como fundamentais no processo de trabalho do Caps. Na elaboração dos projetos terapêuticos, é fundamental que os profissionais de saúde considerem as famílias nas suas singularidades, já que estas apresentam demandas das mais variadas ordens. Entre as quais, Colvero et al. ${ }^{15}$ cita: a dificuldade de lidar com as situações de crise, com os conflitos familiares emergentes, com a culpa, com o pessimismo por não conseguir vislumbrar saídas para os problemas, com o isolamento social a que ficam sujeitos, as dificuldades materiais da vida cotidiana, as complexidades do relacionamento com esse familiar, a expectativa frustrada de cura ou o desconhecimento da doença propriamente dita.

É fundamental, portanto, o reconhecimento da família como um conjunto de pessoas em inter-relação, e que, por isso, é sempre afetada por qualquer doença, sofrimento e/ ou mudança em algum de seus membros. Portanto, é necessário que os profissionais de saúde estejam atentos a toda a complexidade que envolve a família, produzindo cuidado 'com base na experiência da família ao longo do tempo, ou seja, sua história pregressa, atual e perspectivas futuras' $(68)^{16}$. Estar atento à história que envolve o passado da família, o seu presente e aquilo que esta projeta para o futuro, sem dúvidas, é uma importante aposta das equipes de saúde na produção do cuidado que reconheça e legitime o ambiente familiar como espaço de cuidado.

\section{A família como parte da vida social do usuário que compõe sua rede de convivência social}

Capoeirista convoca, ainda, a reconhecer a família como parte da vida social do sujeito, podendo compor a sua rede social e de apoio. Nessa direção, a partir do conhecimento sobre a história de vida familiar de Capoeirista, foi 
possível dar visibilidade para a complexidade do cuidado em saúde mental e sua imbricação com a dinâmica familiar do sujeito com transtorno psíquico.

Desse modo, o cuidado em saúde mental, a partir dos serviços substitutivos, entre eles, o Caps, produz novas tensões nos modos de cuidado em saúde mental, visto que as ações em saúde passam a ter como pauta para a sua elaboração e efetivação o território, ou seja, os lugares onde a vida pulsa, o cotidiano, as relações sociais e as redes dos sujeitos.

A desinstitucionalização, enquanto desconstrução dos modos de lidar com a loucura ${ }^{4}$, traz tensões nas relações de cuidado entre os sujeitos e seus familiares, no sentido de que a família passa a ser reconhecida como uma parte da vida social do sujeito, podendo compor a sua rede de convivência e de relações.

As propostas da reforma psiquiátrica convocam a família a (re)assumir esse lugar, que lhe foi retirado durante a hospitalização de seu membro ${ }^{4}$. Esse lugar, ora assumido, ora interditado e/ou invisibilizado, traz para a cena a necessidade de os trabalhadores de saúde reconhecerem o ambiente familiar como rede social e de apoio dos sujeitos. Tal reconhecimento, por sua vez, garante que os profissionais potencializem as relações familiares, com o intuito de fortalecer as relações sociais dos usuários.

Feuerwerker e Merhy ${ }^{17}$ trazem a discussão sobre os serviços substitutivos em saúde, entre eles, o Caps, destacando que eles podem ser

dispositivos efetivos de tensão entre as novas práticas e o modelo hegemônico e entre veIhos hábitos e lugares que produzem melhorias reais na construção de formas sociais de tratar e cuidar do sofrimento ${ }^{\mathbf{1 7}}$.

Ou seja, esses autores afirmam que em tais serviços pode existir o confronto de práticas e concepções que configuram o trabalho em saúde.

Dialogando com a aposta da família como parte da vida social dos usuários, a mudança dos modelos de cuidado - do hospitalar, longe do convívio familiar, para o territorial, próximo à família - provoca deslocamentos nos modos como a equipe de saúde lida com as estratégias de cuidado.

Ao mesmo tempo que o mundo muda sua forma de ver e de se relacionar com a loucura, também o papel da família na sociedade passa por inúmeras transformações. Muda a forma de se pensar a implicação da família no aparecimento da doença mental, uma vez que a literatura atual sobre o tema coloca a família tanto como a grande causadora do adoecimento psíquico quanto como potente meio de cuidado e melhora ${ }^{6}$.

Problematiza-se, assim, o papel da família como rede de apoio no cuidado em saúde mental, visto que não basta apenas desospitalizar os sujeitos com transtorno mental e (re)inseri-los no ambiente familiar. É preciso garantir a sustentabilidade de sua vida cotidia$\mathrm{na}^{\mathbf{1 4}}$, ou seja, fortalecer seus laços familiares e comunitários, de modo que ele possa acessar diferentes redes no território quando necessitar de apoio.

$\mathrm{O}$ acontecimento descrito neste texto traz para análise a necessidade de se considerar a família como rede de apoio, tendo em vista as apostas de cuidado da equipe para além do grupo de capoeira e da escola. Necessitava-se, também, reconhecer a família como espaço de convivência e rede de apoio para Capoeirista. Esse reconhecimento, por sua vez, possibilita aos trabalhadores ampliarem as suas ações, no sentido de garantirem a sustentabilidade cotidiana desse usuário nas suas redes sociais. Tais ações promovem um suporte para o usuário na busca de estratégias para lidar com seus conflitos e dificuldades ${ }^{15}$.

Nessa perspectiva, as ações pautadas na reforma psiquiátrica buscam contribuir para a criação, o fortalecimento e a manutenção de redes sociais, fatores que podem ser, de fato, determinantes para modificar a trajetória dos usuários $^{\mathbf{1 4}}$. Entre essas redes, a família deve ser vista como um lugar de possível convivência do portador de transtorno mental, mas não deve ser o único nem o obrigatório ${ }^{\mathbf{1 6}}$. 


\section{Conclusões}

O acontecimento convoca a uma visualização da família como aquela que cuida, que disputa planos de cuidado e que também precisa ser cuidada. Além do que, em alguns momentos, como na elaboração do plano de cuidado, ela pode ser invisível para a equipe de saúde, sendo apenas solicitada para se responsabilizar pelo sujeito em sofrimento psíquico. Talvez o mais importante não seja delimitar qual é o lugar que a família deve assumir na produção do cuidado, mas dar visibilidade para as diferentes posições que ela pode assumir no decorrer dos processos cuidadores.

O reconhecimento desses diferentes lugares que a família pode ocupar convida os trabalhadores da saúde a repensarem as suas práticas, e, nesse processo criativo e inventivo que é a produção do cuidado ${ }^{17}$, a constituírem estratégias e ações para as quais a produção de mais redes vivas seja o norte das ações em saúde.

A cartografia da família como aposta no cuidado em saúde mental tem se mostrado um dispositivo fértil para se pensarem os diferentes lugares da família na produção do cuidado. Nesse sentido, percebe-se a necessidade do Caps de redefinir o usuário de quem cuida, assim como a atenção básica fez, ou seja, o cuidado precisa deixar de ser individual para ser familiar.
Radicalizando a aposta de Basaglia ${ }^{18}$, é preciso colocar a doença e o sujeito entre parênteses, para se visualizarem a família e suas relações, e, a partir daí, planejarem-se ações em saúde voltadas para a multidimensionalidade dos ciclos e das trocas familiares, que constituem um sistema em redes.

\section{Colaboradores}

Ferreira TPS (0000-0002-2581-4970)* contribui na sua elaboração com as seguintes atividades: contribuiu substancialmente para a concepção e o planejamento análise e a interpretação dos dados; contribuiu significativamente na elaboração do rascunho e revisão crítica do conteúdo; e participou da aprovação da versão final do manuscrito. Sampaio J (0000-0003-0439-5057)* contribuiu na análise e a interpretação dos dados, na revisão crítica do conteúdo e participou da aprovação da versão final do manuscrito. Oliveira IL (0000-0002-2762-7255)* contribuiu na revisão crítica do conteúdo e participou da aprovação da versão final do manuscrito. Gomes LB (0000-0002-19570842)* contribuiu na revisão crítica do conteúdo e participou da aprovação da versão final do manuscrito. 


\section{Referências}

1. Brasil. Ministério da Saúde, Secretaria de Atenção à Saúde, Departamento de Atenção Básica, Departamento de Ações Programáticas Estratégicas. Cadernos de atenção básica em saúde mental. Brasília, DF: Ministério da Saúde; 2013.

2. Gomes MPC, Merhy EE. Pesquisadores In-mundo: um estudo da produção do acesso e barreira em saúde mental. Porto Alegre: Rede Unida; 2014.

3. Deleuze G, Guattari F. Mil platôs: capitalismo e esquizofrenia. São Paulo: Editora 34; 1995. 96 p.

4. Amarante P. Loucos pela vida: a trajetória da reforma psiquiátrica no Brasil. Rio de Janeiro: Fiocruz; 1995.

5. Barros JO, Mângia EF. Rede social e atenção às pessoas com transtornos mentais: novo desafio para os serviços de saúde mental. Rev. ter. ocup. univ. 2007; (18)3:135-142.

6. Rosa LCS. O cotidiano, as tensões e as repercussões do provimento do cuidado doméstico ao portador de transtorno mental. Saúde debate. 2004; 28(66):28-37.

7. Brasil. Ministério da Saúde, Secretaria de Atenção à Saúde, Departamento de Atenção Básica. Política Nacional de Atenção Básica. Brasília, DF: Ministério da Saúde; 2006.

8. Rolnik S. Cartografia sentimental: transformações contemporâneas do desejo. São Paulo: Estação Liberdade; 1989.

9. Merhy EE. O cuidado é um acontecimento e não um ato [internet]. [s.d.]. [acesso em 2019 jun 21]. Disponível em: file://C:/Users/Mariana/Downloads/o\%20 cuidado\%20e\%20acontecimento\%20e\%20nao\%20 ato.pdf.

10. Carvalho LC. A disputa de planos de cuidado na atenção domiciliar [dissertação]. Rio de Janeiro: Universidade Federal do Rio de Janeiro; 2009.
11. Costa MCL. A cidade e o pensamento médico: uma leitura do espaço urbano. Mercator. 2002; 1(1):61-69.

12. Ferreira TPS, Sampaio J, Souza ACN, et al. Produção do Cuidado em Saúde Mental: desafios para além dos muros institucionais. Interface (Botucatu). 2017; 21(61):373-384.

13. Franco TB, Magalhães H. A integralidade e as linhas de cuidado. In: Merhy EE, Magalhães Júnior HM, Rimoli J, et al. O trabalho em saúde: olhando e experienciando o SUS no cotidiano. São Paulo: Hucitec; 2003.

14. Mângia EF. Notas metodológicas para a pesquisa de campo e análise de entrevistas. São Paulo: Lab. Conexões, FMUSP; 2006.

15. Colvero LA, Ide CAC, Rolim MA. Família e doença mental: a difícil convivência com a diferença. Rev. Esc. Enferm. USP. 2004; 2(38):197-205.

16. Rosa L. Transtorno Mental e o cuidado na família. São Paulo: Cortez; 2003.

17. Feuerwerker LCM, Merhy EE. A contribuição da atenção domiciliar para a configuração de redes substitutivas de saúde: desinstitucionalização e transformação de práticas. Rev. Panam Salud Publica. 2008; 24(3):180-188. [acesso em 2019 jun 21]. Disponível em: https://www.scielosp.org/article/rpsp/2008. v24n3/180-188/.

18. Basaglia F. Escritos selecionados em saúde mental e reforma psiquiátrica. Rio de Janeiro: Garamond; 2010. 336 p.

Recebido em 26/03/2019

Aprovado em 09/04/2019

Conflito de interesses: inexistente

Suporte financeiro: Ministério da Saúde através do Observatório Nacional da Produção do Cuidado no SUS: avalia quem faz, quem pede e quem usa, com sede na Universidade Federal do Rio de Janeiro 